\title{
PHOTOGRAMMETRY AS A METHOD FOR RETRIEVING GEOMETRICAL INFORMATION ON THE 20-TH CENTURY HERITAGE. THE AGIP COLONY IN CESENATICO.
}

\author{
C. Bartolomei ${ }^{1}$, A. C. Benedetti ${ }^{1}$, C. Morganti ${ }^{1 *}$, G. Predari ${ }^{1}$ \\ ${ }^{1}$ Department of Architecture, Alma Mater Studiorum - University of Bologna \\ (cristiana.bartolomei, annac.benedetti, caterina.morganti4, giorgia.predari)@unibo.it
}

\section{Commission II, WG II/8}

KEY WORDS: Digital Heritage Documentation, Structure from motion, Management, Giuseppe Vaccaro, Agip colony, Modeling, Cultural Heritage

\begin{abstract}
:
The aim of this research is the rediscovery of one of Giuseppe Vaccaro's architectural masterpieces thanks to the use of the contents obtained from the survey that was carried out, useful for its architectural representation; the selected building is the Agip colony, which is located on the beach of Cesenatico. The three-dimensional photogrammetry, a science that uses photography as a source of measurement, will be investigated as a method for graphic and metric representation, with the aim to study, in this particular case, the elements composing the facade of this architectural work of the '30s, through the last software born of the Agisoft family, Metashape.
\end{abstract}

\section{INTRODUCTION}

The digitalization of documents, in addition to expanding the range of analysis methods through advanced data cataloging tools, provides the user with the possibility of having an increasingly more accurate and direct relationship with architectural works.

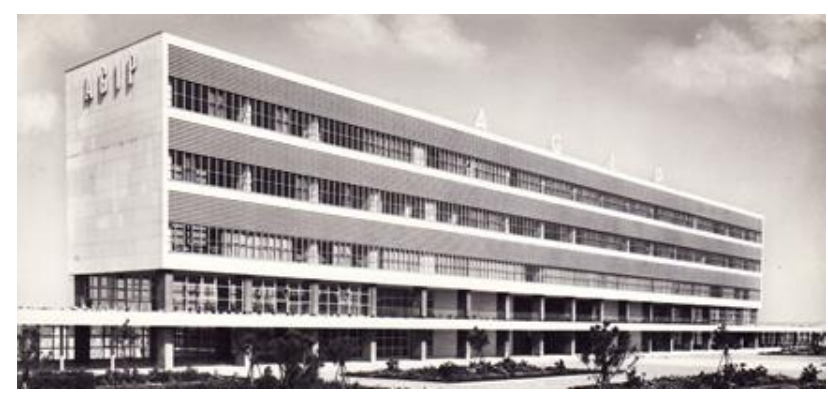

Figure 1. Facade towards the street of the Agip colony at the time of its realization.

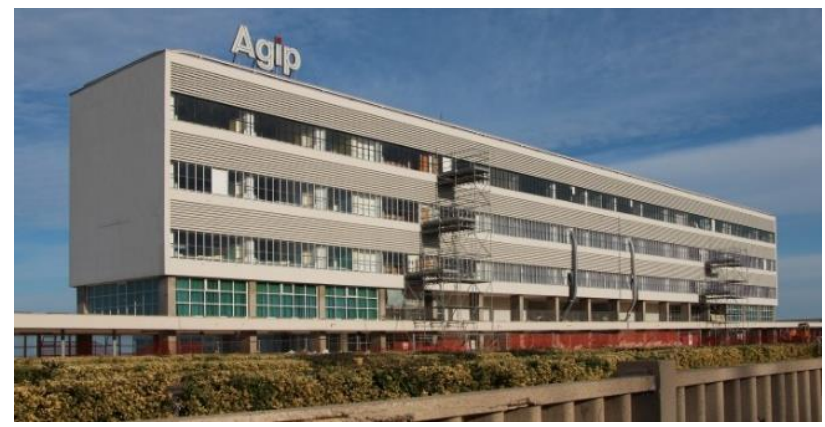

Figure 2. Facade towards the street of the Agip colony nowadays.
In particular, the building that has been chosen to illustrate this process is the Agip Colony designed by Giuseppe Vaccaro, which is located on the beach of Cesenatico (Figure 1, Figure 2) (Basilico, 2000).

Within the projects of Giuseppe Vaccaro, the marine colony of Cesenatico testifies the architect's style in the second half of the 1930s and the transition to the mature phase of his design activity (Balducci, 2005).

At that time, Vaccaro had already completed the phase of his activity using an eclectic style and he was designing an architectural work in a context completely different from his previous experiences: materially, since in the 30 s the site was totally isolated at the extreme southern periphery of the town of Cesenatico, not yet reached by the growth of the urban fabric; and ideally, since the place was far from the center of the political and architectural debate on the Modern style (Cao, 1994).

Free from any external conditioning, Vaccaro focused on a new function, to be designed for a private client; this combination led to the generation of a true modern architecture, where the positioning of the building, the functional needs and the landscape became fundamental (Canali, 2009a).

In fact, the area of the colony was in a situation of total isolation, on a plot measuring $270 \times 80$ meters, marked on the two main sides by the coastal road and the beach, while the two smaller sides faced areas where the construction of two other colonies was planned (Figure 3, Figure 4).

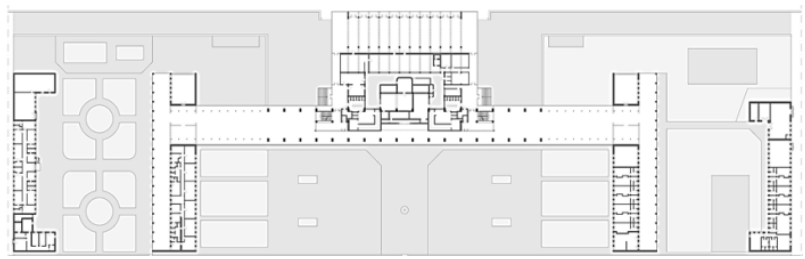

Figure 3. Plan of the whole ground floor of the colony. 

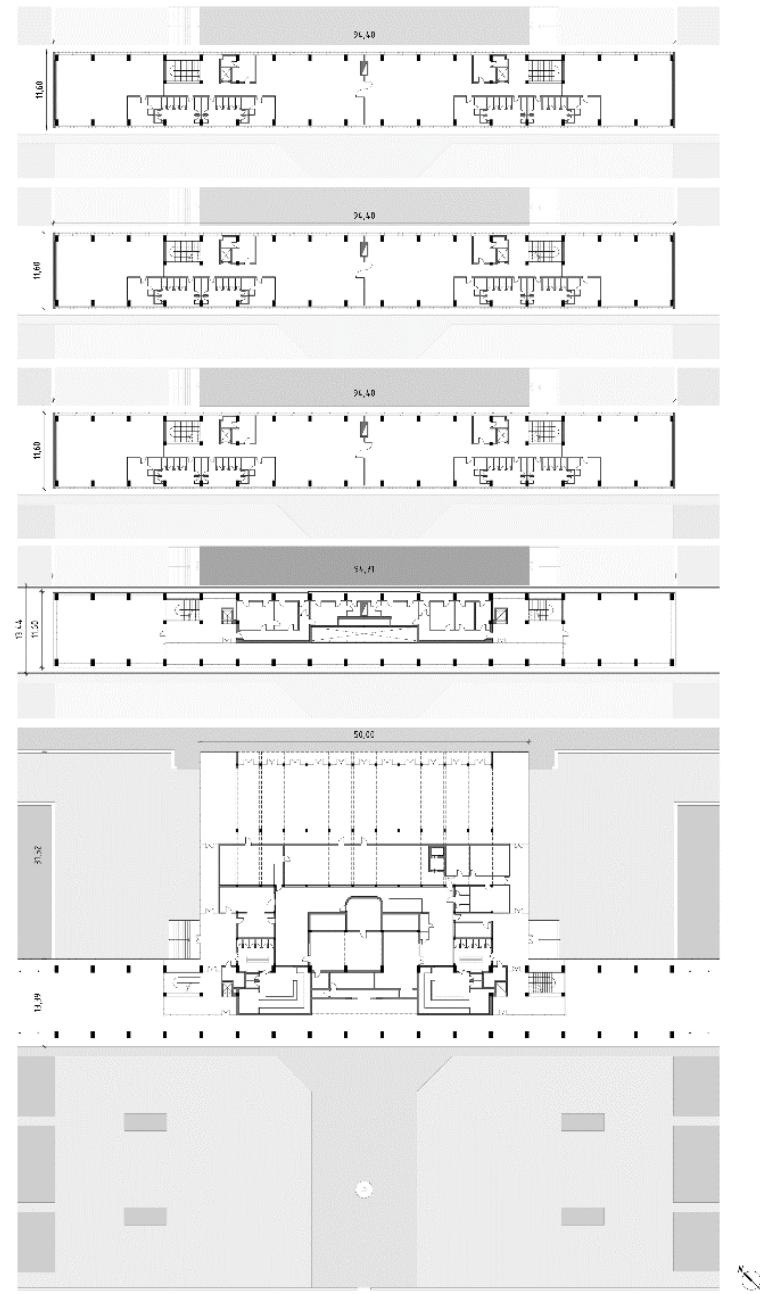

Figure 4. Representation of the floors of the main block (from the ground floor at the bottom, to the fourth floor at the top).

Thanks to the location and the characteristics of the building site, Vaccaro was able to freely develop the topics of the Modern Movement, such as the pure forms, the free design of the floor plans and of the façades, the lightness given by the double pilotis, in a direct relationship with the natural environment, where the landscape is dominated by the horizontal line separating the sky and the sea (Franchini, 2009) (Mulazzani, 2002).

Distributive and structural simplicity, symmetry, functional organization are the characteristics that define the project. These found a direct expression in the complete control of every detail and every component (Giolli, 1938).

The comparison between the photomodeling survey and the historical-iconographic documentation allowed to identify the transformations of the building over time, and this was an essential moment in the process of acquisition of knowledge (Figure 5, Figure 6, Figure 7) (Bianchini et al., 2003a).

The orthophotos obtained from the survey elaboration have been compared with the orthophotos obtained from the historical photos, so as to perform overlaps that will be useful for the knowledge of the transformations occurred over time (Addison et al., 2000) (Chiabrando et al., 2015a).

In fact, using the principles of projective geometry, even from a single photographic image it is possible to create a "photoplan", useful for the metric documentation of extended flat surfaces such as facades (Aicardi et al., 2016a) (Russo et al., 2018a).
The setup of a photoplan is based on the processing and transformation of a frame from a perspective projection to an orthographic projection (Cefalu et al., 2013b) (Suwardhi et al., 2015a).

In order for this transformation to be possible, it is necessary to identify the position of at least five points in space, and they must be found both on the frame and on the tagged object: these points, indicated by appropriate signals (called markers) or identified by natural points, are generally measured with topographic instruments (Strecha et al., 2015) (Stylianidis et al., 2016).

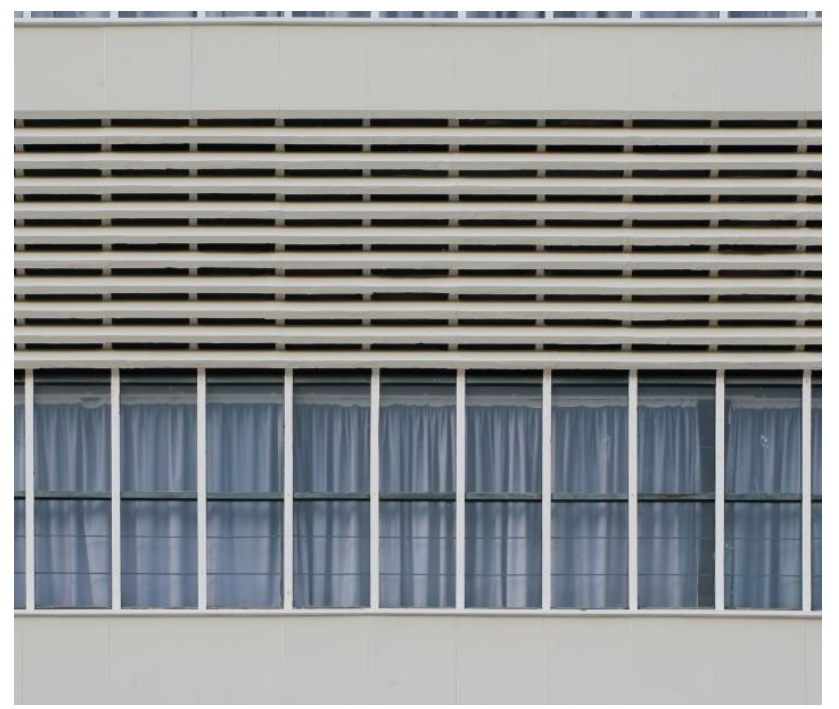

Figure 5. Current image of fixtures towards the street.

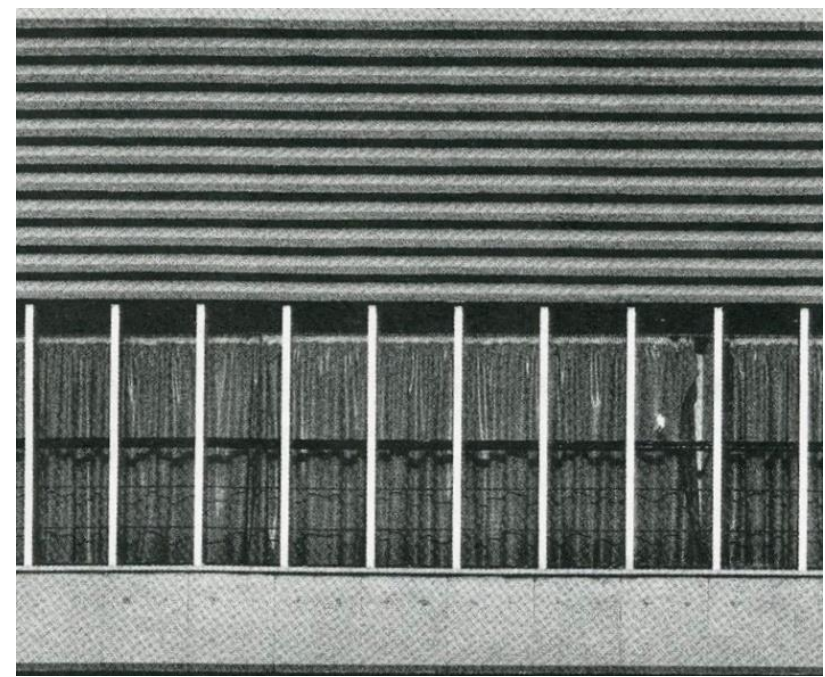

Figure 6 . The fixtures towards the street in the $60 \mathrm{~s}$

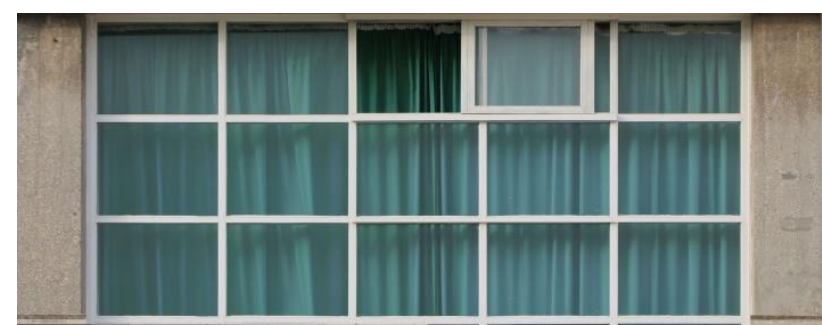

Figure 7. Current image of fixtures towards the sea. 


\section{DESCRIPTION OF THE BUILDING}

The Agip colony in Cesenatico consists of four blocks connected to each other, and an isolated one located at the edge of the area. The high volume of the dormitories, raised on a long series of pillars, is oriented in parallel to the coast and it represents the axis of development of the entire composition.

Facing the sea, it ensures a direct relationship between the sea and the countryside, guaranteeing a visual continuity with the seascape (Istituto Beni Culturali della Regione Emilia-Romagna, 1986).

At its center, the volume of the refectory is connected to the main block; the buildings used for the surveillance staff, the reception and the general services are located at both ends.

The connection between the different parts is ensured by a portico, which was originally open to allow a continuous view of the sea from the road, and then equipped with glass closures on the sea front to protect it from drafts and coastal storms.

An essential part of the project was the gathering square, where the flag-raising ritual was celebrated daily; on it, a chapel dedicated to religious rites faced (Massaretti, 2013).

Regarding the planimetric distribution, the layout centralizes the prevailing functions in the central block and displaces the service functions in the low secondary blocks connected to it.

The planimetric scheme highlights a markedly symmetrical organization that generates a strong differentiation of spaces, both internal and external, and an articulation of surfaces and volumes.

The symmetry of the layout corresponded to the need for division between male and female children.

The spaces with a stronger symbolic and representative value were arranged in sequence along the central axis: the large entrance square used for ceremonies, the management block, dormitories and medical services, and the refectory.

The latter was located at the central axis of the main building, in a square-plan volume with a single floor, facing the sea, which also included general services.

The refectory was a rectangular space with two lateral entrances; the front on the beach consisted of a continuous window open onto the seascape. The shed roof favored the natural lighting (Figura 8).

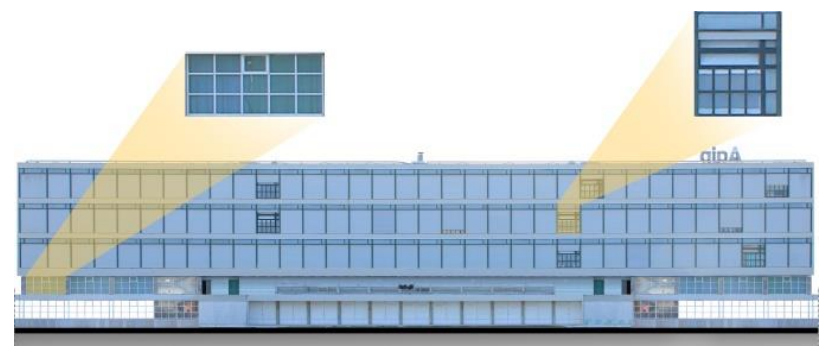

Figure 8. Façade towards the sea.

Behind the refectory, there were the kitchen, with a pantry, the laundry and the wardrobes.

Two staircases within the main volume gave separate access to the dormitories, located on the upper floors and suitable for 300 children. The dormitories were based on the repetition of a module composed of two dorms placed next to a central core containing the stairs and the services. Each dorm included thirty beds; the beds were gathered in small groups without any internal separation system, and they were arranged so as to leave a central distribution corridor to facilitate surveillance. The room for the supervisor ensured the efficiency of the control and was contiguous to the entrance of each dormitory.
The dormitories overlooked the sea on one side and the coastal road on the other. The seafront was equipped with large windows for the circulation of sea air; the front on the road was exposed to the sun, therefore it had external grills and protective curtains that offered the possibility of regulating heat, light and ventilation in relation to the various moments of the day and weather conditions.

The service buildings were oriented orthogonally to the main block, and were delimited by a series of open spaces and small squares with different natural surfaces, such as grass, sand, water or stone. These spaces were intended for activities to be carried out during the days.

A single-storey pavilion was inserted orthogonally to the left of the dormitory volume: on one side, it housed the recreation and writing room for the females, on the other there was the caretaker's house and the reception area.

The portico of the building opened onto a small garden, which was closed on the opposite side by the isolation pavilion. Another pavilion, which was connected to the right side of the dormitory volume, housed the recreation and writing room for males, as well as the service staff rooms.

The office of the director and the administration were inside the main block, on the first floor, in a central position of the whole complex.

The isolation pavilion (nowadays modified and adapted as the caretaker's residence) was the only independent block, originally intended to accommodate children suffering from infectious diseases. Located on the left end of the perimeter, it was oriented to exploit the maximum benefits of air and light.

On the formal level, the project dealt with four fundamental components: the solid wall, the wall cut out of modular openings, the wall engraved by horizontal lines, the scan of the pilotis.

The central block still appears today as a white four-storey monolith with a reinforced concrete frame, whose pillars are not visible on the façade, as they are slightly set back from the outer perimeter. This arrangement had allowed the architect to create a strip of ribbon windows for each level of the building, both on the seafront and on the street front.

The formal solution of the main façades is therefore guided by the horizontal line, which dominates the landscape, too; the twodimensionality of their design, characterized by the rhythmic repetition of continuous glass windows and sunshade strips, generates a strong light-dark effect, which testifies to the role assigned to light by the architect.

The blind walls of the short sides contrast with the glass and sunshades; they are covered with white cromobeton concrete slabs. In the porticos, the transformation of the vertical supports from pillars to thin columns seems to mark the passage from the monumental dimension to the small courtyards' one. As Umberto Cao writes, "the strength of the architectural idea is all in the simplicity and synthesis of its image: low buildings placed at the extreme of the area, but arranged orthogonally to the sea so as not to obstruct the view, a thin horizontal floor on pilotis connecting them, and above, the isolated parallelepiped block of the dormitories.

No obstruction to sight, no fracture between natural elements, no obstacle to the free flow of healthy air".

\section{DATA PROCESSING}

The aim of the activity was to reveal the underlying design, and to extrapolate similarities and differences related to the composition, both for metric and formal aspects (Gaiani, 2001). Different operations can be performed on digital images, from the moment of acquisition until their transfer and processing (Bolognesi et al., 2014a). 
These processing procedures can be grouped into four steps: acquisition; compression; pre-treatment and recovery; processing using the Agisoft Metashape software.

The acquisition is the generation phase of digital images, which can be obtained through digital machines or through laser scanners. In this case, the acquisition took place via digital machines (Förstner et al., 2016).

The second phase is defined as compression. Quantized digital images are defined in the size of the Byte, requiring the use of memory cards for saving.

In the third phase, image processing involves pre-treatment and recovery. The two procedures are aimed at improving the appearance of digital images (enhancement) or aimed at recovering degraded images (restoration) (Grenzdörffer et al., 2015a). Enhancement aims to achieve an image with better features than the original one. While the restoration has the purpose of removing or minimizing the degradation introduced in the image during the acquisition phase. Among the causes of disturbance we can mention: the movement of the object, the noise, the blurring and the distortion of the lenses. There are particular filters that allow to obtain a correct image restoration, when applied with dedicated algorithms; some examples of filters are: Gamma, Camera Raw, K-Nearest neighbor, a filter for expanding the radiometric levels and one for adaptive noise reduction (Luhmann et al., 2014). Image modification techniques can also be used to enhance the radiometric edges, to vary the position of the grey values, or to try to reduce a given radiometric noise on the image or to vary the contrast (Guidi et al., 2006a). These techniques can be classified into families: contrast enhancement (set of techniques that improve the global contrast of the image, based on the equalization of the histogram of the radiometric values) and edge enhancement (the set of algorithms that improve the radiometric gradient in the radiometric border area) (Remondino et al., 2006a). Specifically, since this is digital photogrammetry, we must try to improve the radiometric aspect of the image before returning it. It is therefore necessary to emphasize three fundamental characteristics of digital images: brightness, contrast and the histogram of radiometric values (Remondino et al., 2013b).

The parameter describing the brightness, taken the sample of the image in grey tones $\mathrm{f}(\mathrm{x}, \mathrm{y})$, is given by the average $f_{a}(\mathrm{x}, \mathrm{y})$.

$$
f_{a}=\frac{1}{\mathrm{RC}} \sum_{x=0}^{R-1} \sum_{y=0}^{C-1} f(x, y)
$$

The parameter that describes the contrast is characterized by the standard deviation $\sigma$.

$$
\sigma=\frac{1}{\mathrm{RC}} \sum_{x=0}^{R-1} \sum_{y=0}^{C-1}\left[f(x, y)-f_{a}\right]^{2}
$$

It is thus possible to define the chromatic adjustment of the image as follows:

$$
f_{i j}^{\prime}=\alpha f_{i j}+b
$$

where $f_{i j}^{\prime}=$ components of the modified matrix;

$f_{i j}=$ components of the non-modified matrix;

$\alpha=$ contrast control factor;

$b=$ brightness control factor.
The modification of the factor $b$ leads to a variation of the displacement (positive or negative) of all the pixel values of the image; the consequence is the lightening or darkening of all colors. For this reason, a parameter is added to allow editing on the image without losing information on the saturation of light or dark tones; this function will be non-linear:

$$
f_{i j}^{\prime}=f_{i j} \gamma
$$

where $\gamma=$ coefficient used to increase the detail in a low contrast image, without significantly affecting shadows and light areas.

Furthermore, another factor is considered: the histogram of the radiometric levels. It represents the distribution of grey values, ie a summary of the information contained in an image.

This histogram of the grey values is fundamental to proceed to scale changes, when the present minimum and maximum grey values are known (Remondino et al., 2014a). The fourth and final phase of image treatment is the processing using the Metashape software (Figure 9, Figure 10). The processing within the Metashape program was carried out according to the following phases:

1. Add Photos;

2. Mask Photos, to obtain good results it is necessary to exclude from the selection all the irrelevant elements (such as accidental foreground, background, disturbing elements);

3. Align Photos, in this phase, Metashape identifies the positions of the photography point in space;

4. Build Dense Cloud, the program calculates depth information for each camera, and then combines them into a single dense point cloud;

5. Build Mesh, it is the phase of generation of the mesh starting from the data of the dense cloud;

6. Build Texture for the final achievement of the textured model.

\section{THE ANALYSIS PHASE}

The indirect survey was fundamental for the measurement of the external façades. The camera Canon Reflex Eos 600D camerahas been located in 206 stations using the same focal length, in order to photograph all the points of the façade and to fill, as much as possible, the shadow cones, considering the multiple difficulties due to the presence of vegetation and the busy street (Toschi et al., 2017a). Furthermore, some window frames have been detected; they have been examined and compared with the historical documentation to recognize similarities and differences to the original ones.

In general, we can state that nowadays the building has not been altered from the original idea of the architect, where light was a fundamental characterizing element both for the facades and for the interior spaces.

Regarding the windows, wood fixtures were used with a single frame running along the entire length of the two facades on the second, third and fourth floor.

Two rows of vasistas windows were fixed on that frame, all with shatterproof Securit or Termolux glasses, in white color on the sea front, and with a fixed external white cement grid upstream. Internally, the iron windows were made by the Curtisa company and were formed by a fixed frame and by vasistas elements with masonite panels instead of glasses. 


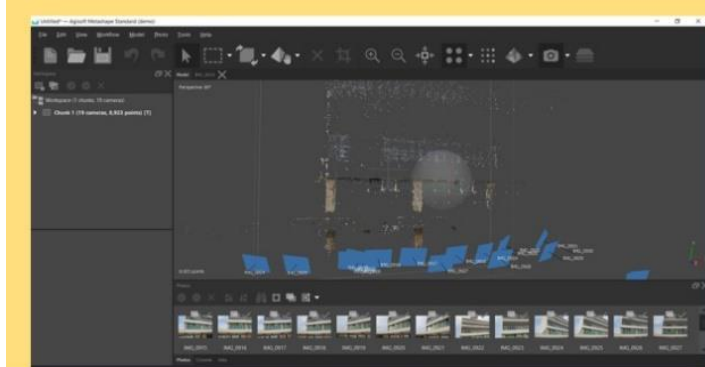

ALIGN PHOTOS

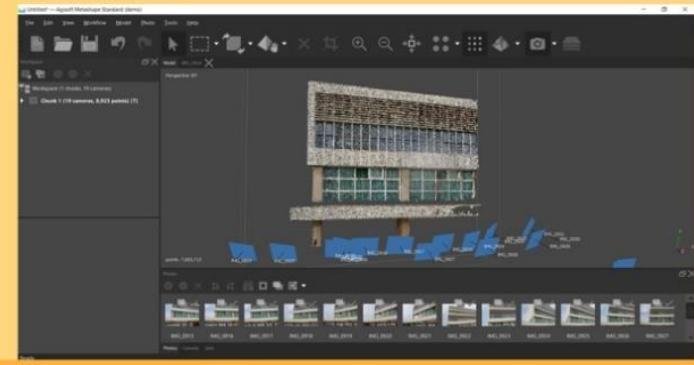

BUILD DENSE CLOUD

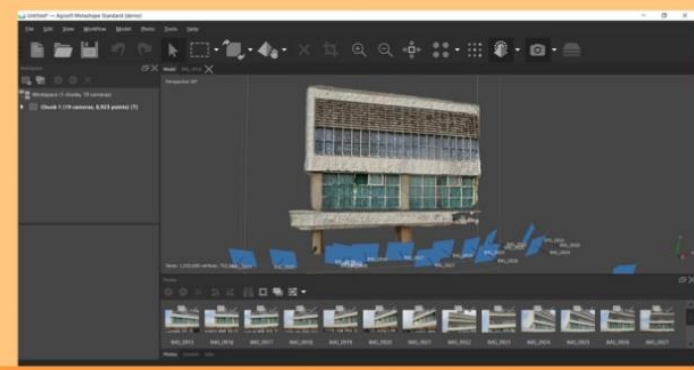

BUILD MESH SHADED

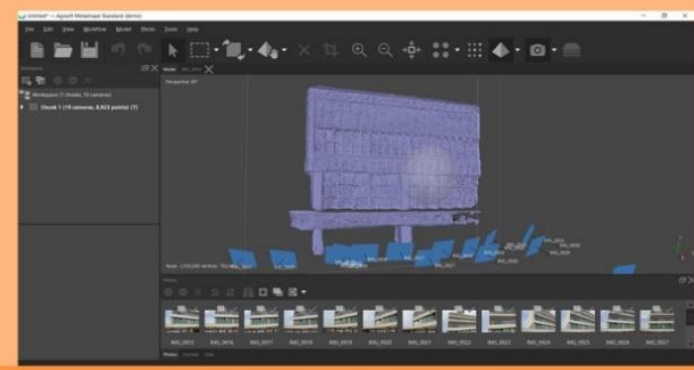

BUILD MESH SOLID

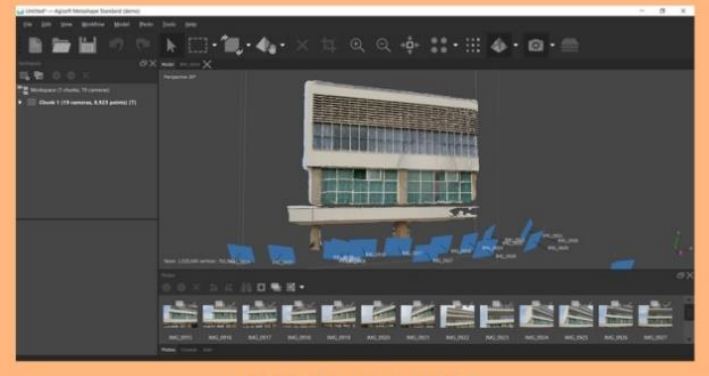

BUILD TEXTURE

Figure 9. Processing using the Metashape software.

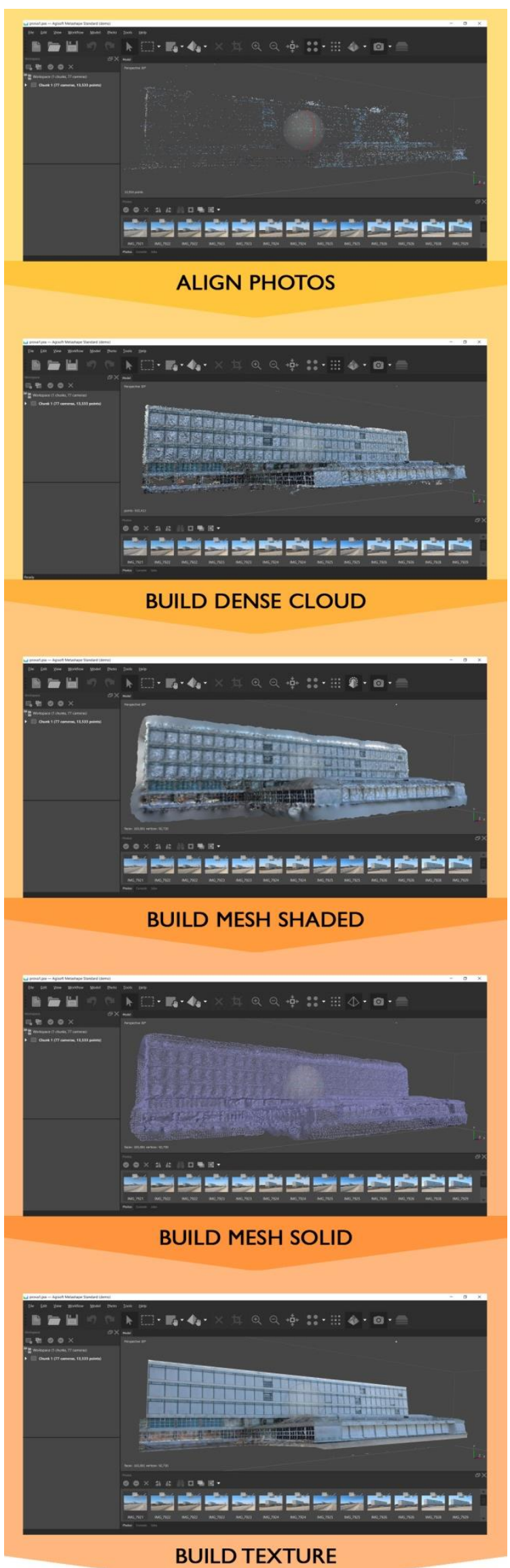

Figure 10. Processing using the Metashape software. 


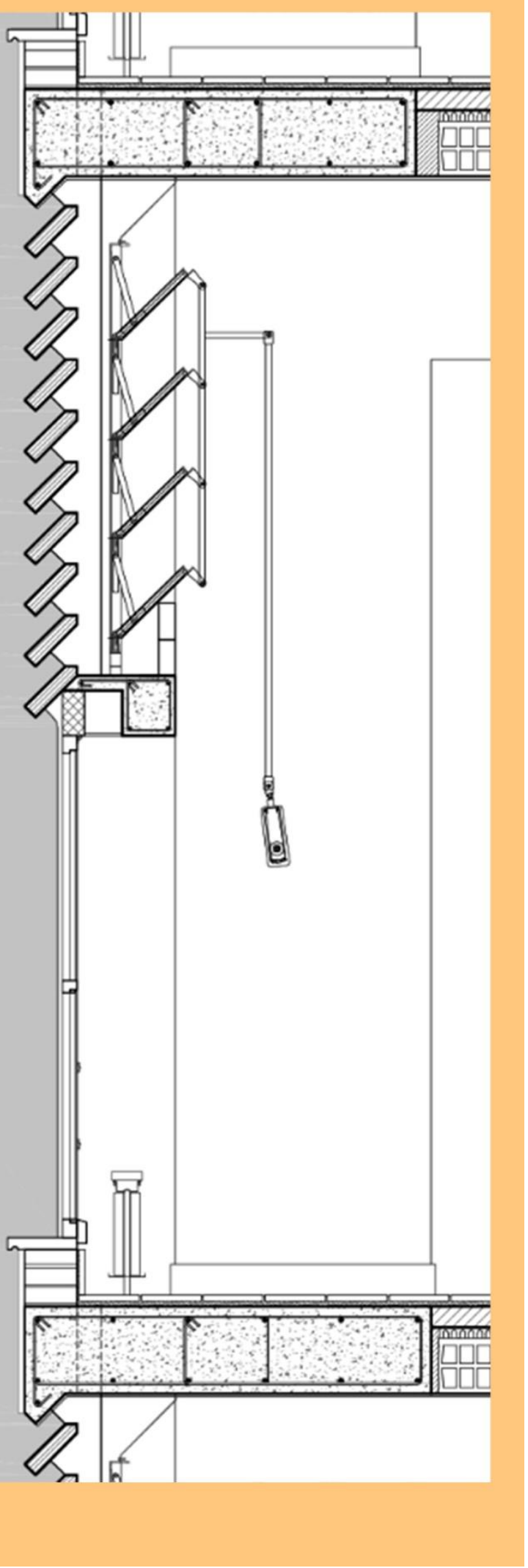

Figure 11. Detail of the fixtures towards the street.

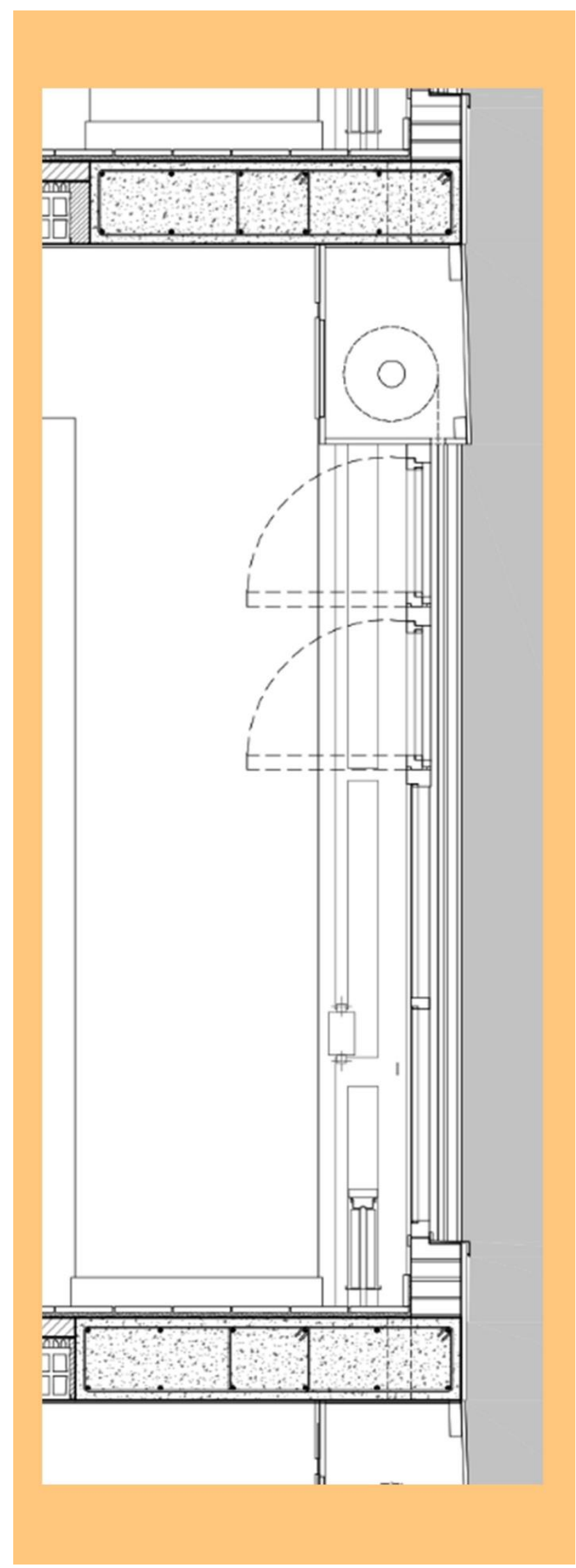

Figure 12. Detail of the fixtures towards the sea. 
The survey has allowed to relate the exterior of the building with its interior, through the characterization of these fixtures, which are the element that best contributes to the representation of the architectural form of the building (Figure 11, Figure 12).

Even the curtains were an essential element for the architect; internally, the windows facing the sea were provided with a rollup blind curtain in order to provide shade, while towards the other side an outdoor curtain was selected in order to avoid overheating of the transparent surfaces.

The curtains were subsequently placed on the inside for practical needs, but they have lost much of their functionality. On the sea front, a PVC shutter has replaced the original curtains, and it has completely altered the original meaning of the solution proposed by the architect.

The installation of the PVC shutter has led to a substantial alteration of the formal sea front solution, eliminating the perception of the original continuous ribbon window and its relation to the horizon.

Furthermore, another relevant and significant transformation was the insertion of partial closures of the originally open paths of the pilotis of the first two floors of the building, applied in the ' $50 \mathrm{~s}$ to protect them from sea storms.

The open spaces and the porticos were also closed with window frames and the two paths next to the refectory, which Vaccaro meant as "light filters covered by thin trestles and curtains", have been transformed in covered corridors (Casciato et al., 2005). As a result and dues to this comparison, it was possible to highlight that the windows on the street side are still the original ones, while they have been partially modified on the sea front. The first reading on the survey outcomes was performed by managing the point cloud in order to obtain critic analysis information that could be overlapped with the data collected, to reach an integrated and accurate survey result. A further step was concluded with the modeling of the single parts consisting the window frame (Ponti, 1943a). This process and documentation work is not regarded as the conclusion but it is considered the basis for a further implementation in the architectural environment.

\section{REFERENCES}

Addison, A. C., and Gaiani, M., 2000. Virtualized architectural heritage: New tools and techniques. IEEE Multimedia, 7 (2), pp. 26-31.

Aicardi, I., Chiabrando, F., Grasso, N., Lingua, A. M., Noardo, F. and Spanò, A., 2016. Uav photogrammetry with oblique images: First analysis on data acquisition and processing. The International Archives of Photogrammetry, Remote Sensing and Spatial Information Sciences 41, pp. 835-842.

Balducci V. (edited by), 2005. Architetture per le colonie di vacanza - Esperienze Europee, Firenze: Alinea.

Basilico, G., 2000. Giuseppe Vaccaro: moderno $e$ contemporaneo. Roma: Peliti associati.

Bianchini, C., Paolini, P., 2003. Rilievo per il restauro e la messa in sicurezza di Hagia Sophia a Istanbul: prime sperimentazioni. Disegnare, Idee, Immagini, 26, pp. 20-31.

Bolognesi, M., Furini, A., Russo, V., Pellegrinelli, A., and Russo, P., 2014. Accuracy of cultural heritage 3D models by RPAS and terrestrial photogrammetry. In: The International Archives of the Photogrammetry, Remote Sensing and Spatial Information Sciences, XL-5:113-19.
Canali, F., 2009. Avanguardia e modernità a Cesenatico: la colonia AGIP "Sandro Mussolini" di Giuseppe Vaccaro (19361939). Note inedite d'archivio e di cantiere. In: Studi Romagnoli, LX, Cesena.

Cao, U. (edited by), 1994. Giuseppe Vaccaro (Colonia marina a Cesenatico, 1936-1938), Roma: Clear.

Casciato, M., Orlandi, P. (edited by), 2005, Quale e quanta: architetture in Emilia-Romagna nel secondo Novecento, Bologna: CLUEB.

Cefalu, A., Abdel-Wahab, M., Peter, M., Wenzel, K., and Fritsch, D., 2013. Image based 3D reconstruction in cultural heritage preservation. In: 10th International Conference on Informatics in Control, Automation and Robotics, pp. 201-205.

Chiabrando, F., Donadio, E., Rinaudo, F., 2015. SfM for orthophoto generation: A winning approach for cultural heritage knowledge. In: International Archives of Photogrammetry, Remote Sensing and Spatial Information Sciences, XL-5/W7 (5), pp. 91-98.

Förstner, W., Wrobel, B., 2016: Photogrammetric Computer Vision. Springer Nature, Cham.

Franchini, F. (edited by), 2009. Colonie per l'infanzia tra le due guerre - storia e tecnica, Santarcangelo di Romagna: Maggioli.

Gaiani, M., 2001. Traduzione dal reale al virtuale in architettura - Un metodo integrato di acquisizione dati e costruzione di modelli digitali tridimensionali. In: Migliari Riccardo (a cura di). Frontiere del rilievo: dalla matita allo scanner $3 D$, Roma: Gangemi Editore, p. 71-85.

Giolli, R., 1938. La colonia marina dell'AGIP a Cesenatico. In: Casabella.

Grenzdörffer, G. J., Naumann, M., Niemeyer, F., Frank, A., 2015. Symbiosis of UAS photogrammetry and TLS for surveying and 3D modeling of cultural heritage monuments - A case study about the Cathedral of St. Nicholas in the city of Greifswald. In: International Archives of Photogrammetry, Remote Sensing and Spatial Information Sciences, XL-1/W4 (1), pp. 91-96.

Guidi, G., Frischer, B., Russo, M., Spinetti, A., Carosso, L., Micoli, L.L., 2006. Three-dimensional acquisition of large and detailed cultural heritage objects. Machine Vision and Applications, Amsterdam: Elsevier, 2006, 17 (6), pp. 349-360.

Istituto Beni Culturali della Regione Emilia-Romagna (edited by), 1986. Colonie a mare, Bologna: Grafis.

Luhmann, T., Robson, S., Kyle, S., Boehm, J., 2014. CloseRange photogrammetry and 3D imaging, 2nd ed., 684. Berlin, Germany: De Gruyter.

Massaretti, P. G., 2013. La colonia "Sandro Mussolini" dell'AGIP a Cesenatico (1937-1938). In: Spiagge urbane. Territori e architetture del turismo balneare in Romagna. Balducci, V., Orioli, V. (edited by), Milano: Bruno Mondadori.

Mulazzani, M. (edited by), 2002. Giuseppe Vaccaro, Milano: Electa.

Ponti, G., 1943. Stile di Vaccaro. In: Stile, n. 27. 
Remondino, F., Spera, M.G., Nocerino, E., Menna, F., Nex, F., 2014. State of the art in high density image matching. Photogrammetric Record, 29 (146), pp. 144-66.

Remondino, F., Spera, M.G., Nocerino, E., Menna, F., Nex, F., Gonizzi-Barsanti, S., 2013. Dense image matching: Comparisons and analyses. In: Proceedings of the Digital Heritage International Congress 2013, (1), pp. 47-54.

Remondino, F., El-Hakim, S., 2006. Image-based 3D modelling: A review. The Photogrammetric Record, 21 (115), pp. 269-91.

Russo, M., Carnevali, L., Russo, V., Savastano, D., Taddia, Y., 2018. Modelling and Deterioration Mapping of Façades in Historical Urban context by Close Range Ultra-Lightweight UAVs Photogrammetry. International Journal of Architectural Heritage, pp. 1-21.

Strecha, C., Zoller, R., Rutishauser, S., Brot, B., Schneider-Zapp, K., Chovancova, V., and Glassey, L., 2015. Quality assessment of 3D reconstruction using fisheye and perspective sensors. ISPRS Annals of the Photogrammetry, Remote Sensing and Spatial Information Sciences, 2(3), 215.

Stylianidis, E., Remondino, F., 2016. $3 D$ recording, documentation and management of cultural heritage. Dunbeath, Caithness: Whittles Publishing.

Suwardhi, D., Menna, F., Remondino, F., Hanke, K., Akmalia, R., 2015. Digital 3D Borobudur - Integration of 3D surveying and modeling techniques. In: International Archives of Photogrammetry, Remote Sensing and Spatial Information Sciences, XL-5/W7 (5), pp. 417-423.

Toschi, I., Ramos, M.M., Nocerino, E., Menna, F., Remondino, F., Moe, K., Poli, D., Legat, K., Fassi, F., 2017. Oblique photogrammetry supporting 3D urban reconstruction of complex scenarios. In: International Archives of the Photogrammetry, Remote Sensing and Spatial Information Sciences, XLII-1/W1 (1), pp. 519-526. 